MINERALOGIA, 44, No 1-2: 3-12 (2013)

DOI: 10.2478/mipo-2013-0001

www.Mineralogia.pl

MineRalogical Society of Poland

Polskie TOWARZYSTWO MINERALOGICZNE

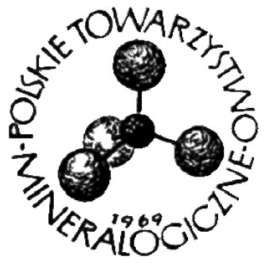

Original paper

\title{
Mössbauer study of Fe phases in terrestrial olivine basalts from southern Egypt
}

\author{
Kamaleldin M. Hassan ${ }^{1, *}$, Julius Dekan ${ }^{2}$ \\ ${ }^{I}$ Department of Radioactive Sedimentary Deposits, Research Sector, Nuclear Materials Authority, P.O. Box 530, \\ Maadi, Cairo,Egypt; email: egy100@yahoo.com \\ ${ }^{2}$ Department of Nuclear Physics and Technology, Faculty of Electrical Engineering and Information Technology, \\ Slovak University of Technology, Bratislava Ilkovicova 3, 81219 Bratislava, Slovakia; \\ email: julius.dekan@stuba.sk \\ * Corresponding author
}

Received: April 4, 2013

Received in revised form: July 17, 2013

Accepted: July 30, 2013

Available online: August 31, 2013

Abstract. Olivine basalts from southern Egypt were studied by ${ }^{57} \mathrm{Fe}$ Mössbauer spectroscopy at 297 and 77 K, and by optical microscopy and X-ray diffraction. The ${ }^{57} \mathrm{Fe}$ Mössbauer spectra show three-magnetic sextets, three doublets of ferrous $\left(\mathrm{Fe}^{2+}\right)$, and a weak ferric $\left(\mathrm{Fe}^{3+}\right)$ doublet that is attributable to a nanophase oxide (npOx). The magnetic sextets relate to titanomagnetite and the $\mathrm{Fe}^{2+}$ doublets to olivine, pyroxene, and ulvöspinel. Variations in the hyperfine parameters of the various Fe components are attributed to changes in the local crystal chemistry. The intensity of oxidation $\left(\mathrm{Fe}^{3+} / \Sigma \mathrm{Fe}\right)$ in the rocks varies from $20-27 \%$ with the oxidized iron largely residing in the titanomagnetite.

Key-words: Egypt, olivine basalts, Mössbauer spectroscopy, spinel minerals, pyroxene

\section{Introduction}

In southern Egypt (Fig. 1), olivine basalts form dikes, sills, sheets and flows of relatively small size within the Cretaceous Nubian Formation that includes numerous small Nubian Sandstone hills (List et al. 1989). These basalts are fine-grained due to the rapid cooling of lavas at the surface and may be ascribed to continental volcanism dating from 
92-20 Ma in what are now the Nubian deserts in Egypt and Sudan (Franz et al. 1983; Satir et al., 1991). They are composed of 41-46.5 wt $\% \mathrm{SiO}_{2}, 13.4-14.5 \mathrm{wt} \% \mathrm{Al}_{2} \mathrm{O}_{3}, 12.7-$ $13.0 \mathrm{wt} \%$ total iron (as $\mathrm{Fe}_{2} \mathrm{O}_{3}$ ) and 2.4-2.6 wt $\% \mathrm{TiO}_{2}$. Contents of total alkalis vary from 5.14-5.31 $\mathrm{wt} \%$, whereas those of $\mathrm{MgO}$ and $\mathrm{CaO}$ lie in the range 10.5-12.6 $\mathrm{wt} \%$.

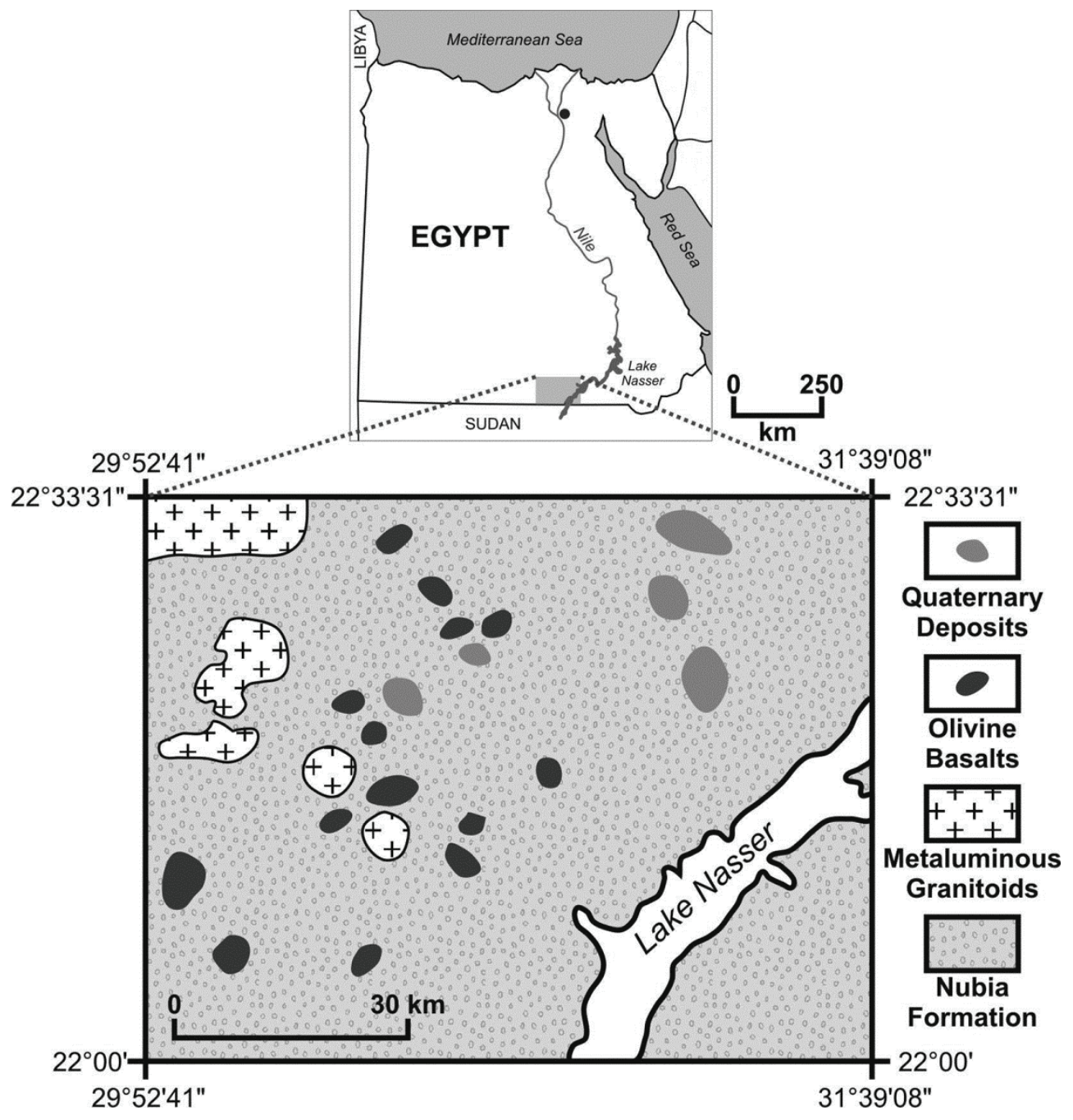

Fig. 1. Geologic map of the study area (revised from Egyptian Geological Survey and Mining Authority, 1981)

${ }^{57} \mathrm{Fe}$ Mössbauer spectroscopy can provide quantitative information concerning iron atoms in geological samples (Hassan 2009 a, b, 2010). Because this method is able to cope with poor mineral crystallinity, it provides a unique probe for studying variations of iron sites in minerals of volcanic rocks. In the present study, olivine basalts from southern Egypt (Fig. 1) were subjected to a detailed ${ }^{57} \mathrm{Fe}$ Mössbauer analysis. The results are particularly 
important in the determination of oxidation state and mineralogy - parameters of considerable geochemical importance in the evaluation of basaltic lava.

\section{Methods}

Two composite samples of the whole-rock olivine basalt, $\mathrm{S} 1_{\mathrm{WR}}$ and $\mathrm{S} 2_{\mathrm{WR}}$, were collected in the field for this study. They are fresh, fine-grained, and massive with a grey to black colour. Sample $\mathrm{S} 1_{\mathrm{WR}}$ was studied using an optical microscope. The rock is holocrystalline and inequigranular and shows doleritic texture. It consists essentially of olivine microphenocrysts embedded in a fine-grained groundmass of plagioclase, olivine, pyroxenes, and opaques (mainly iron oxides). The pyroxenes include diopside and augite. Iron oxides also occur as scattered fine-grained anhedral crystals. Photomicrographs are shown in Fig. 2.
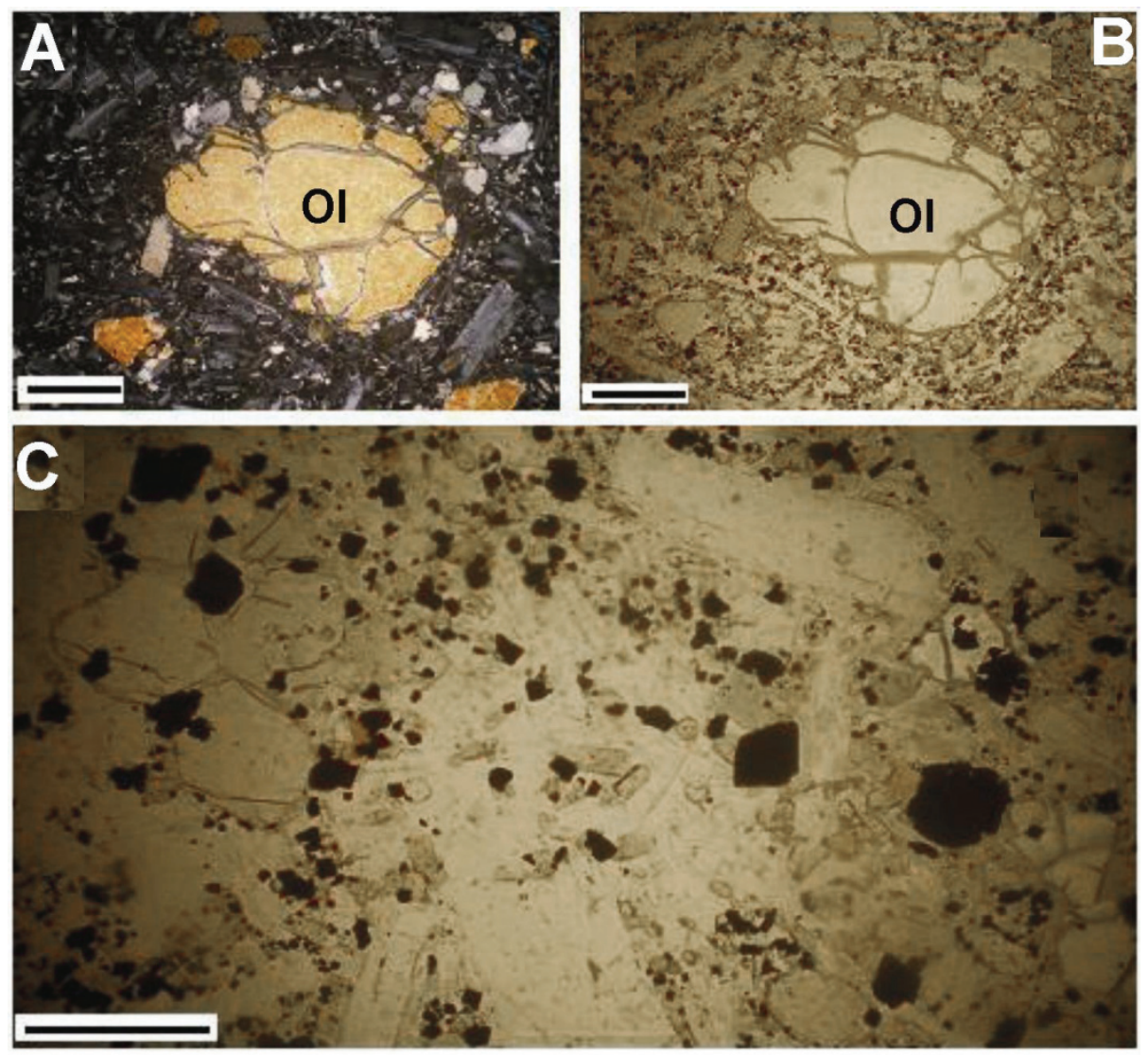

Fig. 2. Photomicrographs of $\mathrm{S} 1_{\mathrm{WR}}$ in cross-polarized light (A) and plane-polarized light (B, C); scale bar $=200 \mu \mathrm{m}$. Olivine $(\mathrm{Ol})$ phenocrysts in a groundmass of fine-grained olivine, pyroxene and iron ore. Anhedral crystals of iron ore (dark) disseminated throughout. 
The two samples were hand ground in copper containers and stored in plastic bottles until analysis. X-ray diffraction (XRD) of the powders involved the use of a Philips PW 1710 diffractometer with $\mathrm{Co}-\mathrm{K} \alpha$ radiation $(\alpha=1.5406 \AA$ ). The resultant diffractograms with minerals identified are presented in Fig. 3. In both samples, in addition to major anorthite $\left(\mathrm{CaAl}_{2} \mathrm{Si}_{2} \mathrm{O}_{8}\right)$, diopside $\left(\mathrm{MgCaSi}_{2} \mathrm{O}_{6}\right)$ and augite $\left[(\mathrm{Ca}, \mathrm{Na})(\mathrm{Mg}, \mathrm{Fe}, \mathrm{Al}, \mathrm{Ti})\left(\mathrm{Si}_{2}, \mathrm{Al}_{2}\right) \mathrm{O}_{6}\right]$ were identified as less abundant components. They are associated with minor analcime $\left(\mathrm{NaAlSi}_{2} \mathrm{O}_{6} \cdot \mathrm{H}_{2} \mathrm{O}\right)$. This analysis did not detect iron oxide or olivine, probably because of their relatively low concentrations. As Fe-oxides in volcanic rocks generally do not exhibit long-range order, they are difficult to study by XRD. However, they are easily identified by Mössbauer spectroscopy.

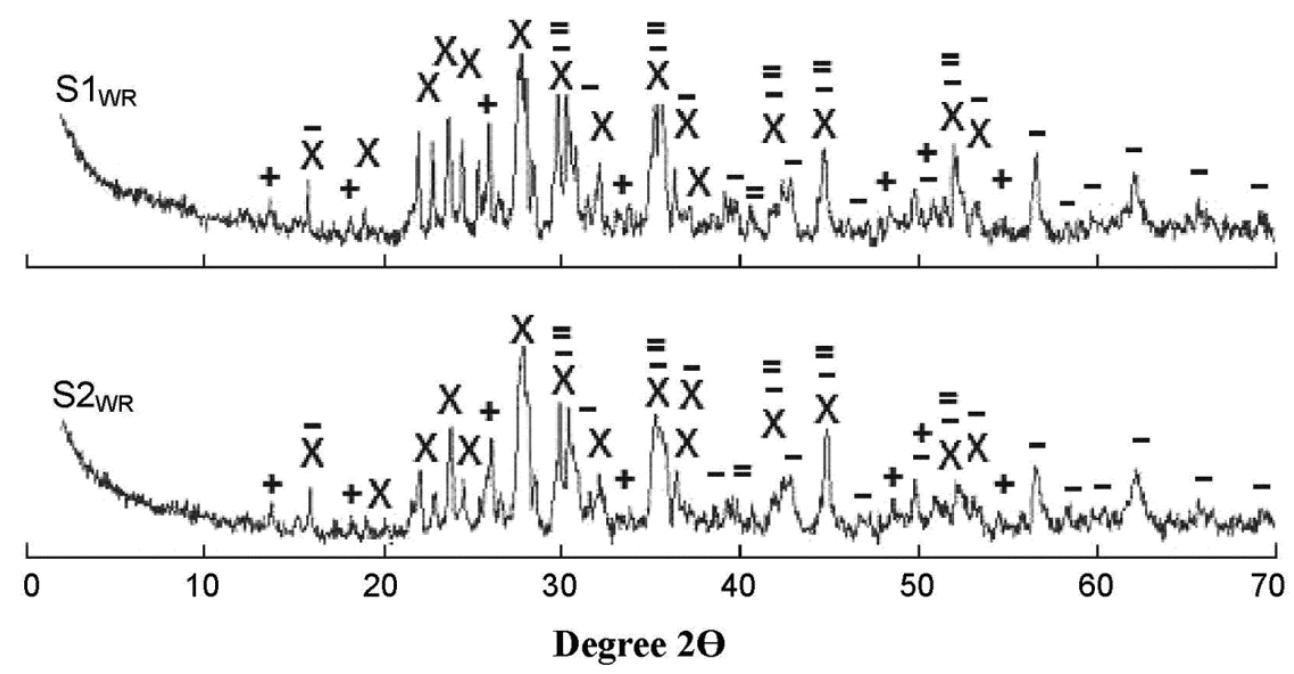

Fig. 3. XRD patterns. Identified mineral peaks are: + , analcime; -, augite; $X$, anorthite; =, diopside. The code numbers of the reference used for the peak identification are 41-1478, 24-201, 11-0654, and $18-1202$

Mössbauer measurements were carried out using a Wissel Mössbauer spectrometer with a ${ }^{57} \mathrm{Co}(\mathrm{Rh})$ source in transmission geometry. A few milligrams of $\mathrm{S} 1_{\mathrm{WR}}$ were separated using a hand magnet, and the separated magnetic fraction is referred to as $\mathrm{S}_{\mathrm{MF}}$. Aliquots of this separated fraction, $\mathrm{S} 1_{\mathrm{MF}}$, along with aliquots of $\mathrm{S} 1_{\mathrm{WR}}$ and $\mathrm{S} 2_{\mathrm{WR}}$ were milled to the finest possible texture in an agate mortar. Mössbauer spectra were obtained for all three aliquots at room temperature $(297 \mathrm{~K})$ and also at liquid nitrogen temperature $(77 \mathrm{~K})$ for $\mathrm{S} 1_{\mathrm{WR}}$. Hyperfine parameters of the spectra including spectral area (RA), isomer shift $(\delta)$, quadrupole splitting $\left(\Delta \mathrm{E}_{\mathrm{Q}}\right)$, line width $(\Gamma)$, and hyperfine magnetic field $(\mathrm{H})$ were refined using the CONFIT fitting software of Žák and Jirásková (2006). Accuracies are $\pm 1 \%$ for RA, $\pm 0.02 \mathrm{~mm} / \mathrm{s}$ for $\delta, \Delta \mathrm{E}_{\mathrm{Q}}$ and $\Gamma$, and $\pm 0.5 \mathrm{~T}$ for $\mathrm{H}$. All $\delta$ values are relative to metallic iron. 


\section{Results and Discussion}

The Mössbauer spectra are shown in Fig. 4 and their parameters are summarized in Table 1 . They are best fitted as three sextets (1-3) and four doublets (1-4). The sextets are attributed to titanomagnetite. The doublets are assigned to three ferrous compounds, namely, olivine (Doublet 1), pyroxene (Doublet 2), and ulvöspinel (Doublet 3) and one ferric phase - nanophase oxide or npOx (Doublet 4). The spectra of $\mathrm{S} 1_{\mathrm{WR}}$ and $\mathrm{S} 2_{\mathrm{WR}}$ have areas of $30-35 \%$ titanomagnetite, $31-33 \%$ olivine, $18-21 \%$ pyroxene, $10 \%$ ulvöspinel and npOx (3-5\%). The spectrum of $\mathrm{S} 1_{\mathrm{MF}}$, on the other hand, is dominated by titanomagnetite sextets $(55 \%)$ and the pyroxene doublet $(27 \%)$, with some contributions from the olivine $(9 \%)$, ulvöspinel (6\%) and npOx (3\%) doublets.

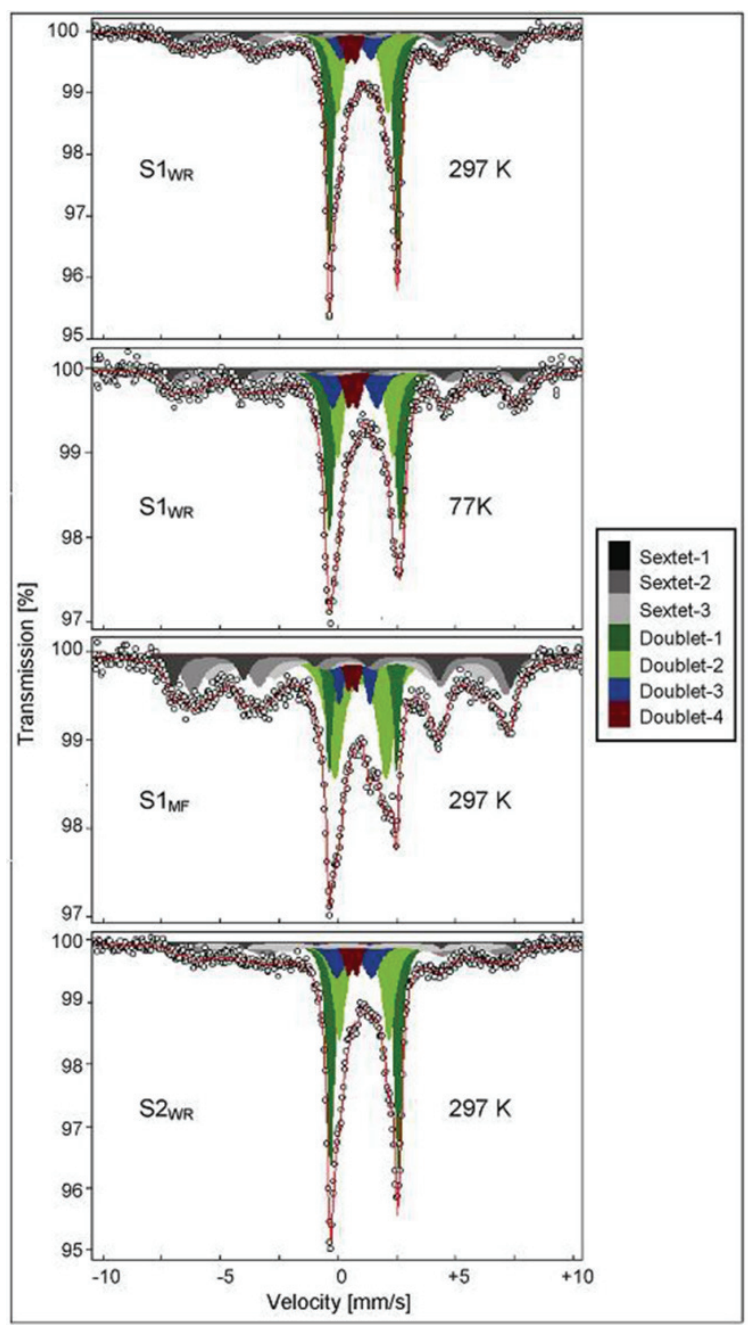

Fig. 4. Mössbauer spectra 
The titanomagnetite sextets have characteristic hyperfine field $(\mathrm{H})$ values of 44.6-46.3 T for Sextet 1, 40.4-45.7 T for Sextet 2 and 33.3-35.8 T for Sextet 3. Sextet 1 originates from iron in tetrahedral coordination (A-site), Sextet 2 from iron in octahedral coordination (Bsite), and Sextet 3 from iron in a valence state between $2+$ and $2.5+(\mathrm{C}-$ site). Sextet 2 and Sextet 3 exhibit considerable a-line broadening, with the latter having the highest line width or $\Gamma$ value $(<1.83 \mathrm{~mm} / \mathrm{s})$. This is probably due to the random distribution of iron cations in different valences and vacancies (Gunnlaugsson et al. 2008). In basaltic magmas, titanomagnetite $\left(\mathrm{Fe}_{3-\mathrm{x}} \mathrm{Ti}_{\mathrm{x}} \mathrm{O}_{4}\right)$ forms a solid solution series between magnetite $\left(\mathrm{Fe}_{3} \mathrm{O}_{4}\right.$ $[\mathrm{x}=0])$ and ulvöspinel $\left(\mathrm{Fe}_{2} \mathrm{Ti}_{1} \mathrm{O}_{4}[\mathrm{x}=1]\right)$ at high temperatures. In titanomagnetites, $\mathrm{Fe}^{3+}$ is replaced by $\mathrm{Fe}^{2+}$ in the $\mathrm{A}$-site and $\mathrm{Ti}^{4+}$ in the $\mathrm{B}$-site, reducing the net ferrimagnetism. Gunnlaugsson et al. (2008) reported a systematic decrease in the average magnetic field along the titanomagnetite series $\mathrm{Fe}_{3-\mathrm{x}} \mathrm{Ti}_{\mathrm{x}} \mathrm{O}_{4}(0<\mathrm{x}<0.8)$ at room temperature. Thus, the magnetic phases in $\mathrm{S}_{\mathrm{WR}}$ and $\mathrm{S} 2_{\mathrm{WR}}$ are predicted to be $\mathrm{Fe}_{2.65} \mathrm{Ti}_{0.35} \mathrm{O}_{4}$ and $\mathrm{Fe}_{2.58} \mathrm{Ti}_{0.42} \mathrm{O}_{4}$, respectively. Spatial variations of titanomagnetite composition can be useful for revealing aspects of the evolution of basaltic lavas. In a study of a thick (30-60 m) basaltic lava flow from the Roza flow field of the Columbia River Basalt, Audunsson et al. (1992) identified three zones with different magnetic properties. The upper zone $(\leq 20 \mathrm{~m}$ thick $)$ has more oxidized titanomagnetite grains, approaching pure magnetite, while the basal layer $(\leq 5 \mathrm{~m}$ thick) has the least oxidized grains $(\mathrm{x}=0.68)$.

The olivine doublet (Doublet 1), with line width $(\Gamma)$ values of $0.29-0.49 \mathrm{~mm} / \mathrm{s}$, has quadrupole splitting $\left(\Delta \mathrm{E}_{\mathrm{Q}}\right)$ and isomer shift $(\delta)$ values varying from 2.87-3.06 and from $1.12-1.19 \mathrm{~mm} / \mathrm{s}$, respectively. These parameters are consistent with ferrous $\left(\mathrm{Fe}^{2+}\right)$ ions in octahedral coordination. In principle, olivine has two octahedral sites for $\mathrm{Fe}^{2+}$ and $\mathrm{Mg}^{2+}$ (namely M1 and M2) which are completely overlapped at temperature below ca $300 \mathrm{~K}$. Natural olivine is a member of a continuous solid solution series, i.e., $\mathrm{Mg}_{2} \mathrm{SiO}_{4}$ (forsterite) and $\mathrm{Fe}_{2} \mathrm{SiO}_{4}$ (fayalite). In this series, the $\mathrm{Fe}^{2+}$ is partially replaced by $\mathrm{Mg}^{2+}$, an ionic process that causes a localized distortion of the electron cloud at the ferrous site and, thus, increases its $\Delta \mathrm{E}_{\mathrm{Q}}$. There is a significant negative correlation between the $\Delta \mathrm{E}_{\mathrm{Q}}$ and olivine fayalite $\mathrm{mol} \%$ (Menzies et at. 2001). Using this relationship and the $\Delta \mathrm{E}_{\mathrm{Q}}$ value of olivine in $\mathrm{S} 1_{\mathrm{WR}}$ and $\mathrm{S} 2_{\mathrm{WR}}$ at room temperature (Table 1), the olivine composition of the two samples is predicted to be 75 and $55 \mathrm{~mol} \%$ fayalite, respectively.

The pyroxene doublet (Doublet 2), with line width $(\Gamma)$ values of $<0.81 \mathrm{~mm} / \mathrm{s}$, has $\Delta \mathrm{E}_{\mathrm{Q}}$ values varying from $2.10-2.36 \mathrm{~mm} / \mathrm{s}$ and $\delta$ values varying from $1.02-1.20 \mathrm{~mm} / \mathrm{s}$. This doublet seems to represent a mixture of the two $\mathrm{Fe}^{2+}$ octahedral coordination sites $\mathrm{M} 1$ and M2 as is evidenced by larger $\Gamma$ values in comparison with the olivine doublet.

The ulvöspinel (Doublet 3 ) has $\delta$ values of $0.68-0.79 \mathrm{~mm} / \mathrm{s}$ and $\Delta \mathrm{E}_{\mathrm{Q}}$ of $1.31-1.88 \mathrm{~mm} / \mathrm{s}$. The $\delta$ values deviate from the diagnostic value $(0.9 \mathrm{~mm} / \mathrm{s})$ reported for well-ordered, synthesized ulvöspinel where iron exists only as ferrous ion (Soresu et al. 2012). This suggests that the ulvöspinel of the olivine basalt has undergone oxidation. Ulvöspinel tends to oxidize to magnetite plus ilmenite during subsolidus alteration of the host rocks (Wikipedia Foundation, Inc., 2013), causing significant changes in the hyperfine parameters (Soresu et al. 2012). 
Mossbauer parameters.

\begin{tabular}{|c|c|c|c|c|c|c|c|c|}
\hline Sample & $\begin{array}{l}\text { Temp. } \\
{[\mathrm{T}]}\end{array}$ & $\begin{array}{l}\text { Spectral } \\
\text { Line }\end{array}$ & $\begin{array}{l}\mathrm{H} \\
{[\mathrm{T}]}\end{array}$ & $\begin{array}{l}\Delta \mathrm{E}_{\mathrm{Q}} \\
{[\mathrm{mm} / \mathrm{s}]}\end{array}$ & $\begin{array}{l}\delta \\
{[\mathrm{mm} / \mathrm{s}]}\end{array}$ & $\begin{array}{l}\Gamma \\
{[\mathrm{mm} / \mathrm{s}]}\end{array}$ & $\begin{array}{l}\text { RA } \\
{[\%]}\end{array}$ & Assessment \\
\hline \multirow[t]{20}{*}{$\mathrm{S} 1_{\mathrm{WR}}$} & 297 & & & & & & & \\
\hline & & Sextet-1 & 44.7 & 0.04 & 0.23 & 0.69 & 7 & Site A-Titanomagnetite \\
\hline & & Sextet-2 & 41.6 & -0.03 & 0.56 & 1.12 & 18 & Site B-Titanomagnetite \\
\hline & & Sextet-3 & 35.8 & -0.21 & 0.70 & 1.06 & 7 & Site C-Titanomagnetite \\
\hline & & Total & & & & & 32 & \\
\hline & & $(\mathrm{WA})^{*}$ & 41.0 & -0.02 & 0.52 & 1.01 & & \\
\hline & & Doublet-1 & & 2.91 & 1.14 & 0.33 & 33 & Oct. $\mathrm{Fe}^{2+}$-Olivine \\
\hline & & Doublet-2 & & 2.16 & 1.09 & 0.57 & 21 & Oct. $\mathrm{Fe}^{2+}$-Pyroxene \\
\hline & & Doublet-3 & & 1.32 & 0.79 & 0.74 & 9 & Tet. $\mathrm{Fe}^{2+}$-Ulvöspinel \\
\hline & & Doublet-4 & & 0.39 & 0.61 & 0.39 & 5 & Oct. $\mathrm{Fe}^{3+}$-npOx \\
\hline & 77 & & & & & & & \\
\hline & & Sextet-1 & 46.3 & 0.04 & 0.25 & 0.51 & 5 & Site A-Titanomagnetite \\
\hline & & Sextet-2 & 45.7 & -0.03 & 0.59 & 1.19 & 14 & Site B-Titanomagnetite \\
\hline & & Sextet-3 & 41.4 & -0.21 & 0.86 & 1.30 & 16 & Site C-Titanomagnetite \\
\hline & & Total & & & & & 35 & \\
\hline & & $(\mathrm{WA})^{*}$ & 43.8 & -0.04 & 0.66 & 1.14 & & \\
\hline & & Doublet-1 & & 3.06 & 1.19 & 0.49 & 31 & Oct. $\mathrm{Fe}^{2+}$-Olivine \\
\hline & & Doublet-2 & & 2.36 & 1.20 & 0.53 & 18 & Oct. $\mathrm{Fe}^{2+}$-Pyroxene \\
\hline & & Doublet-3 & & 1.88 & 0.76 & 0.74 & 11 & Tet. $\mathrm{Fe}^{2+}$-Ulvöspinel \\
\hline & & Doublet-4 & & 0.40 & 0.67 & 0.44 & 5 & Oct. $\mathrm{Fe}^{3+}$-npOx \\
\hline \multirow[t]{10}{*}{$\mathrm{S} 1_{\mathrm{MF}}$} & 297 & & & & & & & \\
\hline & & Sextet-1 & 44.8 & 0.03 & 0.21 & 0.61 & 11 & Site A-Titanomagnetite \\
\hline & & Sextet-2 & 41.6 & -0.03 & 0.54 & 0.99 & 22 & Site B-Titanomagnetite \\
\hline & & Sextet-3 & 35.8 & -0.21 & 0.59 & 1.40 & 22 & Site C-Titanomagnetite \\
\hline & & Total & & & & & 55 & \\
\hline & & $(\mathrm{WA})^{*}$ & 39.9 & -0.09 & 0.49 & 1.08 & & \\
\hline & & Doublet-1 & & 2.89 & 1.12 & 0.29 & 9 & Oct. $\mathrm{Fe}^{2+}$-Olivine \\
\hline & & Doublet-2 & & 2.21 & 1.02 & 0.81 & 27 & Oct. $\mathrm{Fe}^{2+}$-Pyroxene \\
\hline & & Doublet-3 & & 1.31 & 0.76 & 0.45 & 6 & Tet. $\mathrm{Fe}^{2+}$-Ulvöspinel \\
\hline & & Doublet-4 & & 0.37 & 0.67 & 0.36 & 3 & Oct. $\mathrm{Fe}^{3+}$-npOx \\
\hline \multirow[t]{10}{*}{$\mathrm{S} 2_{\mathrm{WR}}$} & 297 & & & & & & & \\
\hline & & Sextet-1 & 44.6 & 0.09 & 0.26 & 0.33 & 2 & Site A-Titanomagnetite \\
\hline & & Sextet-2 & 40.4 & -0.16 & 0.58 & 1.31 & 16 & Site B-Titanomagnetite \\
\hline & & Sextet-3 & 33.3 & -0.19 & 0.79 & 1.83 & 12 & Site C-Titanomagnetite \\
\hline & & Total & & & & & 30 & \\
\hline & & $(\mathrm{WA})^{*}$ & 37.9 & -0.15 & 0.64 & 1.45 & & \\
\hline & & Doublet-1 & & 2.87 & 1.12 & 0.35 & 32 & Oct. $\mathrm{Fe}^{2+}$-Olivine \\
\hline & & Doublet-2 & & 2.10 & 1.11 & 0.58 & 23 & Oct. $\mathrm{Fe}^{2+}$-Pyroxene \\
\hline & & Doublet-3 & & 1.49 & 0.68 & 0.82 & 11 & Tet. $\mathrm{Fe}^{2+}$-Ulvöspinel \\
\hline & & Doublet-4 & & 0.38 & 0.62 & 0.37 & 4 & Oct. $\mathrm{Fe}^{3+}-\mathrm{npOx}$ \\
\hline
\end{tabular}

(WA)*- Weighted average 
As shown in Table 1, $\Delta \mathrm{E}_{\mathrm{Q}}$ values for the pyroxene-, olivine-, and ulvöspinel doublets increase with decreasing temperature from $297 \mathrm{~K}$ to $77 \mathrm{~K}$. The $\delta$ values for the pyroxeneand olivine doublets also increase in the same direction. The temperature dependence of the $\Delta \mathrm{E}_{\mathrm{Q}}$ in a $\mathrm{Fe}^{2+}$ compound comes from the valence contribution to the electric field gradient that is temperature-dependent because this contribution is determined by the Boltzman distribution of the sixth 3d electron over the 3d level (Ingalls 1964). The temperature dependence of $\delta$, on the other hand, results from the second-order Doppler shift effects (e.g., Patrusheva et al. 2010). Unequivocal temperature effects have been reported for the quadrupole splitting of olivine and pyroxene, for which the gradients of $(-11.2 \pm 1.2) \cdot 10^{-4}$ and $(-7.3 \pm 2.3) \cdot 10^{-4} \mathrm{~mm} / \mathrm{s} / \mathrm{K}$, respectively, have been derived (Agresti 2012).

The npOx (Doublet 4), with relative spectral areas or RA values of $3-5 \%$, has $\Delta \mathrm{E}_{\mathrm{Q}}$ and $\delta$ varying from $0.38-0.40$ and $0.60-0.67 \mathrm{~mm} / \mathrm{s}$, respectively. The $\Delta \mathrm{E}_{\mathrm{Q}}$ and $\delta$ values are similar to those reported for octahedral paramagnetic $\mathrm{Fe}^{3+}$ in the ordinary chondritic meteorite Thylacine Hole-001 (Cadogan, Devlin 2012). NpOx is a generic name for any ferric-rich product of oxidative alteration, such as ferric oxyhydroxide, and superparamagnetic (small particle) hematite and goethite (Morris et al. 2008).

The extent of oxidation $\left(\% \mathrm{Fe}^{3+}\right)$ in $\mathrm{S} 1_{\mathrm{WR}}$ and $\mathrm{S} 2_{\mathrm{WR}}$ due to the presence of titanomagnetite is estimated to be 16 and $22 \%$, respectively, using a model relating average magnetic field to composition in the $\mathrm{FeO}-\mathrm{TiO}_{2}-\mathrm{Fe}_{2} \mathrm{O}_{3}$ ternary system (Gunnlaugsson et at. 2008). In addition, the samples contain $4-5 \% \mathrm{Fe}^{3+}$ (npOx), as determined by Mössbauer spectroscopy (Table 1). The overall oxidation state in these samples is higher $(20-27 \%)$ than the oxidation value $(\sim 14 \%)$ reported for mid-ocean ridge basalt (Christie et al. 1986). The interpretation of magmatic oxidation states is by no means simple. Magmas are subject to a number of oxidizing factors including crystallization, assimilation, and loss of volatiles. Post-eruptive solutions further oxidize the resultant lavas. In iron-bearing minerals, the oxidation ratio $\left(\mathrm{Fe}^{3+} / \Sigma \mathrm{Fe}\right)$ is a function of mineral crystal structure and the availability of oxygen or $f \mathrm{O}_{2}$ at crystallization (McCanta et al. 2003). For example, olivine does not allow significant $\mathrm{Fe}^{3+}$ to enter its crystal lattice and, thus, may not record changes in magmatic $f \mathrm{O}_{2}$. The $f \mathrm{O}_{2}$ effect on oxidation in a geologic system is complicated by temporal- and spatial variability in the pressure and temperature of the system, composition heterogeneity (Kress, Carmichael 1991), and quenching conditions (Audunnson et al. 1992). The iron-titanium oxides are usually late crystallization products in basaltic melts at low pressure (e.g., Hill, Roeder, 1974). Their particle sizes depend largely on the cooling rate of the magma and their composition on the availability of oxygen. In a quenched melt, iron-titanium oxide minerals may constitute only a minor fraction of the crystalline rock, or may be absent. For slower-cooling igneous magmas, the Fe-Ti oxide grains might be larger and show compositional evolution (e.g., O'Reilly 1984).

\section{Conclusions}

In this study, we have identified the Fe-bearing phases in the terrestrial olivine basalts of southern Egypt. The principal components are olivine, pyroxene, titanomagnetite, ulvöspinel, and a nanophase oxide. We have observed the effects of cooling on their hyperfine parameters and have been able to estimate the extent of oxidation in the rocks. 
Acknowledgements. The authors thank the staff of the "Toshki Uranium Study and Evaluation Project" of the Egyptian Nuclear Materials Authority for their field assistance E.M. Abuzeid for taking the photomicrographs and D. S. Helman for valuable comments on the manuscript. We gratefully acknowledge constructive suggestions from the Editor (Marek Michalik) and two anonymous reviewers that significantly strengthened the article. Costs for the $\mathrm{Co}(\mathrm{Rh})$ source were provided by the Science and Technology Assistance Agency of the Slovak Republic (grant no. APVV-0516-10).

\section{References}

Agresti, D. (2012). Temperature dependence of the quadrupole splitting of olivine and pyroxene from Plains of Gusev Crater on Mars. Hyperfine Interactions, 208(1-3), 117-121. DOI: 10.1007/s10751-011-0405-6.

Audunnson, H., Levi, S., \& Hodges, F. (1992) Magnetic property zonation in a thick lava flow. Journal of Geophysical Research, 97(B4), 4349-4360. DOI: 10.1029/91JB01508.

Cadogan, J.M., \& Devlin, E.J. (2012). Mössbauer study of the Ordinary-Chondrite meterorite Thylacine Hole-001. Hyperfine Interactions, 208(1-3), 91-94 (2012). DOI: 10.1007/s10751-011-0417-2.

Christie, D.M., Carmichael, I.S.E., \& Langmuir, C.H. (1986). Oxidation states of mid-ocean ridge basalt glasses. Earth and Planetary Science Letters, 79, 397-411. http://dx.doi.org/10.1016/0012-821X(86)90195-0.

Egyptian Geological Survey and Mining Authority (1982). Geological map of Egypt, scale 1:2,000,000. Abbasyia, Cairo, Egypt: Geological Survey and Mining Authority.

Franz, G., Puchelt, H., \& Pasteels, P. (1983). Petrology, geochemistry and age relations of Triassic and Tertiary volcanic rocks from SW Egypt and NW Sudan. Journal of African Earth Sciences, 6, 335-352. http://dx.doi.org/10.1016/0899-5362(87)90077-7.

Gunnlaugsson, H.P., Rasmussen, H., Kristjánsson, L., Steinthorsson, Helgason, Ö., Nørnberg, P., Madsen, M.B., \& Mørup, S. (2008). Mössbauer spectroscopy of magnetic minerals in basalt on Earth and Mars. Hyperfine Interactions, 182(1-3), 87-101. DOI: 10.1007/s10751-008-9714-9.

Hassan, K.M. (2009a). Rhyolite-dacite-trachyandesite association: a Mössbauer spectroscopy study. Hyperfine Interactions, 192(1-3), 101-107. DOI: 10.1007/s10751-008-9904-5.

Hassan, K.M. (2009b). Characterization of granites by ${ }^{57} \mathrm{Fe}$ Mössbauer spectroscopy. Mineralogia, 40(1-4), 95106. DOI: $10.2478 / \mathrm{v} 10002-009-0008-\mathrm{x}$

Hassan, K.M. (2010). Valences and site characteristics of iron in radioactive magmatic veins (Egypt): A Mössbauer and chemical study. Mineralogia, 41(1-2), 23-33. DOI: 10.2478/v10002-010-0003-2.

Hill, R.E.T., \& Roeder, P.L. (1974). The crystallization of spinel from basaltic liquid as a function of oxygen fugacity. Journal of Geology, 82, 709-729.

Ingalls, R. (1964). Electric-field gradient tensor in ferrous compounds. Physical Review, 133(3A), 787-795. DOI: 10.1103/PhysRev.133.A787.

Kress V.C., \& Carmichael I.S.E. (1991). The compressibility of silicate liquids containing $\mathrm{Fe}_{2} \mathrm{O}_{3}$ and the effect of composition, temperature, oxygen fugacity and pressure on their redox states. Contributions to Mineralogy and Petrology, 108, 82-92. DOI: 10.1007/BF00307328.

List, F.K., El-Gaby, S., \& Tehrani, R. (1989). The basement rocks in the Eastern and Western Deserts and Sinai. In M. Hermina, E., Klitzsch \& S. List (Eds.), Stratigraphic lexicon and explanatory note to the geologic map of Egypt 1:500000 (pp. 33-56). Cairo, Egypt: Egyptian General Petroleum Corporation.

McCanta, C., Rutherford, M.D., Dyar, M.D., \& Delaney, J.S. (2003). $\mathrm{Fe}^{3+} / \Sigma \mathrm{Fe}$ ratios in pigeonite as a function of fO2: a preliminary investigation. Proceedings - 34th Lunar and Planetary Science Conference, 17-21 March 2003 (Abstract 1361). Lunar and Planetary Institute. League City, Texas, U.S.A.

Menzies, O.N., Bland, P.A., \& Berry, F.J. (2001). An ${ }^{57}$ Fe Mössbauer study of the olivine solid solution series: Implications for meteorite classification and deconvolution of unequilibrated chondrite spectra. Proceedings 32nd Lunar and Planetary Science Conference, 12-16 March 2003 (Abstract 1622). Lunar and Planetary Institute. League City, Texas, U.S.A.

Morris, R.V., McKay, G.A., Agresti, D.G., \& Li, L. (2008). Mössbauer and electron microprobe studies of density separates of Martian Nakhlite MIL03346: Implications for interpretation of Mössbauer spectra acquired by the 
Mars exploration rovers. Proceedings - 39th Lunar and Planetary Science Conference, 10-14 March 2008 (Abstract 2458). Lunar and Planetary Institute. League City, Texas, U.S.A.

O'Reilly, W. (1984). Rock and mineral magnetism. Glasgow and London/ New York: Blackie/Chapman and Hill.

Patrusheva, D.G., Oshtrakh, M.I., Petrova, E.V., Grokhovsky, V.I., \& Semionkin, V.A. (2010). ${ }^{57}$ Fe hyperfine interactions in M1 and M2 sites of olivine from Omolon meteorite: study using Mössbauer spectroscopy. Hyperfine Interactions, 197(1-3), 295-300. DOI: 10.1007/s10751-010-0188-1.

Satir, M., Morteani, G., \& Fuganti, A. (1991). K-Ar ages, Sr-isotopic compositions and chemistry of late Cretaceous-Tertairy basalts from the Nubian Desert (northern Sudan). European Journal of Mineralogy, 3 , 943-955.

Soresu, M., Xu, T., Wise, A., Diaz-Míchelens, M., \& McHenry, M.E. (2012). Studies on structural, magnetic and thermal properties of $x \mathrm{Fe}_{2} \mathrm{TiO}_{4}-(1-x) \mathrm{Fe}_{3} \mathrm{O}_{4}(0 \leq x \leq 1)$ Pseudo-binary System. Journal of Magnetism and Magnetic Materials, 324, 1453-1462. http://dx.doi.org/10.1016/j.jmmm.2011.12.012.

Wikipedia Foundation, Inc. (2013). Ulvöspinel. Retrieved March 29, 2013, from http://en.wikipedia.org/wiki/Ulvöspinel.

Žák, T., \& Jirásková, Y. (2006). Confit: Mössbauer spectra fitting program. Surface and Interface Analysis, 38(4), 710-714. DOI: $10.1002 /$ sia.2285. 